\title{
1921-1922 Yıllarında Ermeni Komitelerinin ve Patrikhanenin İstanbul'daki Faaliyetleri
}

\author{
Doç. Dr. Bülent ÇUKUROVA*
}

\section{ÖZET}

Kurtuluş Savaşı yıllarında İstanbul'daki Türk haberalma elemanları, Ermeni komiteleri ve işgalcilerin her türlü faaliyetini izleyerek, düzenli olarak Ankara'ya rapor ettiler. Komiteler, patrikhane, İngitere'nin İstanbul temsilcisi ve Yunanlılarla birlikte Anadolu hareketinin başarısızll ğı için her türlü komplonun içinde bulundu.

$B u$ raporların verdiği bilgiler ışı̆̆ında, Ermeni komiteleri İstanbul'daki özellikle Hiristiyanlardan finans sağlamaya çalışmış, Batı ve Balkan devletleriyle işbirliğine girmiş, Anadolu'dan gọ̧̈en yerli Ermeniler Batılı işgalciler tarafindan Marmara bölgesine yerleştirilerek, bölgedeki Ermeni nüfusu arttırılmaya çalışılmıştır. Bunlara ek olarak komiteler, İstanbul'u yeni Türk devletinden koparabilmek amactyla çalışmalar yürütmüş̧ür.

\section{The Activities of Armenian Commities and Patriarchates in İstanbul During 1921-1922 \\ ABSTRACT}

During the Turkish Independence War with the Turkish news agency and Ankara watched very closely the activities of Armenians commitees, the patriarchates, and the relations between Armenians and the Balkan States, and even the minorities which work in the railroad lines, and the Armenians immigrants which came to Istanbul.Britishes, Greeks, Armenian commitees, Patriarchate and native compradors, by working together and with the help of the organizations which they assembled, they tried to prevent the Anatolian movements. Their aim was not put the nationalists in the Balkan States even if at that time the national movement in Anatolia couldn't be prevented but the developments didn't be occured which they hoped and it caused their behaviour any result.

• Çukurova Üniversitesi Eğitim Fakültesi. 
This study is about the activities of powers which try to prevent the Kemalist movements in the European side, from the middle of 1921 until big Attack's.

Mütarekeden sonra Secret Service Adana, Kayseri, Niğde, Maraş, Malatya, Diyarbakır, Konya, Sivas ve bunların ilçelerinde İngilizlere çalışan, Ermenilerden oluşan bir haberalma ağı kurmuş olmasına karşın, 1922 ortalarında artık bu bölgede Müslüman olmayan istihbarat elemanı kalmadı ${ }^{1}$. İngilizlerin haber kaynaklarının önemli bir kısmını da şimendifer hatlarında görev yapan azınlıklar oluşturdu. Bunlar bir yandan Anadolu'daki gelişmeleri İstanbul'daki haber merkezine iletirken, diğer yandan komitecilerin Anadolu'ya sızmasını sağladı. Bu durumu Ankara'da fark ettiğinden örneğin, "Şark Şimendiferleri Kumpanyası Müdürü” Küçükyan, İstanbul'daki Türk haberalma elemanları tarafından yakından izlendi ${ }^{2}$.

Yine Mütareke sonrası İstanbul'daki Ermeni komite ve derneklerinin merkezleri Avrupa'ya taşındı. Amerika, İtalya, İngiltere, Cenevre, Brüksel ve Beyrut'ta birer Ermeni temsiciliği kuruldu'. İstanbul'da komitelerin birer delegeleri bırakıldı. Bu delegelerden, merkezle ilişkilerini sürdürmeleri ve merkezin emirleri doğrultusunda faaliyet gösterme görevi verildi. Bunlar A.Darapirhamyan, O.Agopyan, Tarosyan, A.Manok, B.Karagözyan, İdareciyan, Taşkiyan, Çınaryan, Kalpacıyan, Tahdoryan, Karteryan, Dr. Altunyan, Parsihyan, Uttüciyan, B. Armenak ve Misakyan idi. Delegelerin ilk çalışmaları Patrikhaneyi ve Patrikhane genel meclisini yanlarına çekmek oldu. Toplanan delegeler Patrikhane mensuplarından Naroyan Mesrup'u başkan seçtiler ${ }^{4}$.

Taşnakların İstanbul Şubesi ve Anadolu genel merkezi Beyoğlu Kabristan sokağı 37 numaradayd $1^{5}$. Şube, İsviçre merkezi Başkanı Noradunkyan ile sürekli haberleşme içindeydi. İletişim Şevariş Misakyan tarafından sağlanıyordu ${ }^{6}$. Parti üyeleri, çıkarları uğruna İstanbul'da iktidarda etkin konuma gelmeyi amaçlayan işbirlikçi Hürriyet-İtilaf ve Necat-İtila Fırkaları ile de ortak çalışmalara girdiler, onların bazı toplantılarına katıldılar?. Bunlarla birlikte Ermeni komiteleri içinde şiddet ve eylemlerle sorunların çözülemeyeceğine, sorunun siyasetle halledilmesi gerektiğine inanan gruplar da bulunmakta idi ${ }^{8}$. Örneğin 1922 Mayısında bazı ruhaniler ve Taşnakların şiddet politikasına karşı çıkan bazı Ermeniler bir kurul oluşturarak, Ermeni sorunları ile yalnız bu kurulun uğraşacağını, heyetin herhangi bir devlete bağlı olmayacağını, Ermeni sorunları için en yüksek başvuru yeri olarak Uluslar Cemiyeti'ni tanıyacaklarını, kurul politikalarının

1 TíTE Arş. K.39/14439.

${ }^{2}$ TíTE Arş. 39/10887-108, 14458, 14573, 14584.

${ }^{3}$ TITE Arș. 39/14507.

${ }^{4}$ TiTE Arş. 39/14599.

${ }^{5}$ TiTE Arş. 39/13243, 13252 .

${ }^{6}$ TiTE Ars. 39/13243.

${ }^{7}$ TITTE Arş.. 39/13252, 13241, 13256, 14391.

${ }^{8}$ TITE Arş. 39/14470. 
açık olacağını açıkladılar ve bu açıklama nedeniyle hem İngilizler, hem şiddet yanlısı Taşnaklardan tehditler aldılar, kiliselerdeki vaaz ve ögütler bu kurulun kararları doğrultusunda yapılmaya çalışıldı. Aynı tehditler Ermeni gazetecilerin, izleyecekleri siyaseti belirlemek üzere gerçekleştirilen toplantı üzerine de yapıldı9. 1922 Haziran sonlarında Taşnak Fırkası'nın Londra merkezi üyelerinden Arusyan İstanbul'a gelerek partinin emirlerini iletti. Fakat patrikhane kurulu bu emirlere kayitsız şartsız uymayı reddetti. Bundan yaklaşık iki ay sonra patrikhaneye gönderilen Taşnak Fırkası kongre kararları da bir tepki görmedi ${ }^{10}$. Durum öyle göstermektedir ki Patrik Zaven'in bir Taşnak Partisi üyesi gibi çalışmasına karşın, patrikhane kurulu, patrikhanenin bir Taşnak Fırkası şubesi olarak çalıştırılmasını engellemiştir. 1922 sonlarında Patrikhane kurulunun İngiltere ve Ermeni komiteleri dışında bir politika izleme girişimi, bazı patrikhane üyelerinin İstanbul'da Fransız Generali Pelle ile ilişkiye girmeleri, Patrikhane cismani üyelerinden birinin Paris'e gidip siyasi görüşmelerde bulunması İngiltere ve Tașnak Fırkası'nın tepkisine neden oldu. Merkezi Cenevre'de bulunan "Ermeni Milliyetperverler komitesi" tarafından hazırlanan ve İstanbul İngiltere Siyasi Temsilcisi Ryan tarafından Patrikhaneye sunulan bir mektupla, patrikhane 1918 kararlarını açıklamakla tehdit edilerek, İngiltere'nin uygulayacağı politikalara uymaya zorland ${ }^{11}$.

1921 yılı içinde Kınalıada'da bulunan "Ermeni İttihad Kulübü" üyelerine askeri eğitim vermeye başladı ${ }^{12}$. Adaya gelen Ermeni gençleri için çadırlar kurularak, eğitimleri için istihkam malzemeleri, patlayıcı maddeler hazırlandı. 1922 Ocak ayında Ermeni Komiteciler, İstanbul'da gerçekleşecek olası ayaklanmayı organize etmek, Türk liderlere karşı suikastler düzenlemek amacıyla Tokatlıyan'da bir fedai derneği oluşturarak, gönüllü kayıtları yaptılar.Dernek Başkanlığına Tahtacıyan, yardımcılığına ise İblaganyan getirildi ${ }^{13}$. Bu Derneğin Yönetim Kurulu üyelerinden, Paris'te bulunan General Antranik, aynı zamanda "Ermeni Milli Müdafaa Heyeti" Başkanı idi ${ }^{14}$.

Haziran 1922 sonlarında yine Kınalıada'da bulunan bir tiyatroda yapılan toplantı Amerika'dan gelen Silyan adlı bir komiteci başkanlığında açıldı. Katılımcılar Ermeni Patrikhanesi yetkilileri, Taşnak Fırkası'nın ileri gelenleri, Ramgavar Fırkası üyeleri ve Sitraklardı. Hınçaklar toplantıya katılmadı. Toplantıda Gülbenkyan, Noradunkyan ve Sivaslıyan'dan gelen mektuplar okundu, komitelerin tek çatı altında birleşmesi onayland ${ }^{15}$. Yine Amerika'dan gelen Şahamyoryan'ın bu toplantıdaki önerisiyle, 3 Temmuz'da bir toplantı yapılarak, 15 Temmuz'da Bulgaristan'da yapılacak

${ }^{9}$ TiTE Arş. 39/14443.

${ }^{10}$ TITE Arş. 39/14424, 14503

${ }^{11}$ TITE Arș. 39/14487.

${ }^{12}$ TITE Arș. 39/13242.

${ }^{13}$ Yönetim Kurulu, Jagadamard Gazetesi sahibi Vartanis Dikyan, General Antranik, Şenmikyan, K. Tabalyan, Vahram Ekmekciyan ve Şevariş Misakyan idi,

${ }^{14}$ TITTE Arș. 39/13262, 13243, 14556.

${ }^{15}$ TITE Arş. 39/14519, 14576. 
Ermeni genel Kongresi'ne katılımcı olarak Jağadamard gazetesi yazarı Sarkis ve Jul isimli komiteciler seçilmiştir ${ }^{16}$.

Mütareke döneminde Ermeni gazetecilerin komiteler içinde aktif rol oynadıkları gözlenmektedir. Bu dönemde Taşnaksütyun Jagadamard gazetesini çıkarırken, Ramgavar-Azadegan Fırkası Sumral-Liberal gazetesini çıkarmakta idi. Diğer Ermeni gazeteleri siyasete fazla yer vermezken, yalnızca Türk aleyhtarı yazılar yazan ve bunun dozunu 1922 sonlarında iyice artıran Jogovartisyan-Jamanak gazetesi Ermeni tezlerini savunmuştur ${ }^{17}$

Komiteler yapacakları ihtilali gerçekleștirebilmek için, örgütlerinin ekonomik kaynaklarını sağlamak zorunda idiler. Komiteler Mondros Mütarekesi'nin imzalanmasindan hemen sonra, Avrupa ve Amerika'da ne doğu Anadolu'yu, ne Ermenistan'ı hiç görmemiş Ermeniler ve Amerikalılar arasında Büyük Ermenistan'ı kurma yolunda propaganda çalışmaları başlattılar. Bu propagandalar başarılı oldu ve milyonlarca dolar bağış topland ${ }^{18}$. İstanbul'da da zengin Ermeniler bu yolda bilinçlendirilmeye çalışılıyordu. Örneğin 1922 Haziranında Nişantaşı'ndaki Ermeni Nortoburos Okulunda yapılan toplantıya Ermeni tüccarlar ve komitelerin ileri gelenleri davet edildi. Bu toplantıda Okul Müdürü Hindliyan yaptığı konuşmada, okulun amaçları, gelişmesinin nasıl sağlanabileceği yanında, Ermenistan'ın geleceğini de içeren, uzun, siyasi bir konuşma yapt ${ }^{19}$. Ermeni Müdafaa Heyeti Ermeni kilise ve okullarında toplantılar yaparak, Halıcıoğlu'ndaki yerli Ermenilerle ${ }^{20}$, Çukurova ve Kafkas mültecilerini komiteye üye yapıp, birer mecidiye toplayarak, bu parayla Avrupa'dan silah ve mühimmat getirmeyi hedefledi. Heyetin başkanlığına başmürettip Dikran Doğramacıyan geldi $^{21}$. Taşnaksütyun komitecileri de benzer bir girişimle mali güçlerini artırmak amacıyla, ticaretle uğraşıp, yerli Ermenilerden para topladılar ${ }^{2{ }^{2}}$.

Kulübün bu politikası ve Taşnak Partisi, uygulamalarında başta İngilizler olmak üzere, yerli Rumlar ve Yunanlılar tarafından desteklendi.

Taşnaklar Büyükada'daki Rum ve Ermeni okullarını, Üsküdar'daki bir Ermeni yetimhanesini silah, cephane depoları haline getirerek, Kumkapı ve Samatya bölgesinde örgütlendiler, Yunan subayları tarafından yerli Rumlar ve Ermenilere istendiği kadar silah dağıtıldd ${ }^{23}$. Bu hareketle planlanan, ulusal kuvvetler İstanbul'a girdiği takdirde veya Paris'te Barıș Konferansı kararları Türkler yararına çıkacak olursa ${ }^{24}$ azınlıklar tarafından bir ayaklanma

${ }^{16}$ TITTE Arş. 39/14519.

17 TiTE Arș. 39/14568.

${ }^{18}$ Malkasian, Mark, The Disintegration of the Armenian Cause in the United States, 1918-1927, Middle East Studies 16 (1984) s.356.

${ }^{19}$ TITE Arş. 39/14499.

${ }^{20}$ TiTE Ars. 39/14464.

${ }^{21}$ TiTE Arş. 39/14464.

${ }^{22}$ TITE Ars. 39/13242, 14464, 14577.

${ }^{23}$ TITE Arş. 39/10895-145, 14509

${ }^{24}$ TITE Arş. 39/13262, 14556. 
çıkarılmasını sağlamaktı ${ }^{25}$. İşin ilginç yanı, bu hareket içinde rantları İstanbul'un işgal kuvvetlerinde kalmasına bağlı olan Türk işbirlikçilerin de bulunmasiydi ${ }^{26}$. Ermeni komitecilerinden Vahram Ekmekciyan'ın ifadesiyle hareket zamanı ve talimatı kendilerine İngilizlerce bildirilecekti ${ }^{27}$. Azınlıklar, işgal kuvvetlerinin İstanbul'u Türklere bırakmaları olasılığına karşı, şehir Türklere geçtiği takdirde katledileceklerini ileri sürmekteydiler. Hatta Aralık 1921 'de Beyoğlu'nda Türklerin fener alayı yapmaları dahi azınlıkların bu yolda propaganda yapmalarına neden oldu ${ }^{28}$.

İngilizlerin örgütlemesi ile 24 Mayıs 1922 'de Hınçak ve Taşnak partilerinin İstanbul şubeleri birleşme kararı aldılar ${ }^{29}$. Bu birleşmeye karşın komiteler zaman zaman bağımsız hareket etti. Örneğin 1922 Haziran sonunda Londra'da yapılacak olan Taşnak Fırkası Kongresine katılımcı olarak, Taşnaklar yaptıkları toplantıyla kendi başkanlarından Polatyan'ı seçtiler $^{30}$.

Haziran ve Temmuz 1922'de de İstanbul'daki çeşitli Ermeni kuruluşları bir araya gelerek toplantılar yaptılar. Haziran ayında Barış Konferansı'na gidecek üyelerin belirlenmesi amaciyla bütün Ermeni ve Rum komiteleri bir araya gelerek, toplantı için iki üye seçtiler. Toplantıda Ermeni ve Rumlara yapıldığı iddia edilen kıyım ile ilgili sahte belgeler oluşturularak, bu olaya tanıklık etmek üzere işbirlikçilerden Hasan Fehmi, İbrahim, Sadık ve İsmail Hakkı isimli kişiler saptand ${ }^{31}$. Aynı toplantıda Bogos Nubar ve Noradunkyan'a mektuplar yazılarak, İzmir boşaltılacak olursa, buradaki "tüm hıristıyanların Türkler tarafından öldürüleceğine" ilişkin Yunan hükümeti ve İtilaf devletlerine birer nota verilmesi istendi. Ĕger İzmir ve yöresi Türklere bırakılırsa, Ermeni ve Rum komitelerinin, İstanbul'da da yapmayı planladıkları gibi Türklere karşı koyacakları vurguland ${ }^{32}$. Bu propagandalar mütarekeden sonra başlamış, Anadolu hareketinin başarıları karşısında kızışmışı.

Temmuz 1922 'de Paris'te bulunan Ermeni temsilciler istifa etti. Yeni oluşturulan kurulun başkanlığına seçimle Gabriel Noradunkyan, müsteşarlığına Param, üyeliklere ise Dr.Tarosyan, Sinanyan, Arşak

${ }^{25}$ TITE Arş. 39/14401.

${ }^{26}$ TiTE Arş. 39/13258. 25.9.1922

${ }^{27}$ TiTE Arş. 39/14581.

${ }^{28}$ TiTE Arş. 39/14401, 14545 .

${ }^{29}$ İki ayrı belgede bu konu ile ilgili farklı bilgiler verilmektedir. Birinci belgede bu birleșmeyi sağlayanın Murad Kürekciyan olduğu (TİTE Arş. 39/13256), ikinci belgede ise birleşmenin Paris'teki Ermeni Barış Komitesi Başkanı Hadisyan ile Necat ve İtila'daki Taşnak temsilcisi, İngiliz Haberalması üyesi Simon olduğu belirtilmektedir. Ayrıca birleşmeyi 12 Mayıs olarak gösteren bu belgede, birleşmede Erkan-1 Harb Bnb.Nuri isimli bir subayın da etkili olduğu yer almaktadır. Bu subay büyük olasılıkla Necat-İtila veya Hürriyetİtilaf'a yakın subaylardan olmalıdır (TITE Arș.39/10888-40).

${ }^{30}$ TITE Ars. 39/14489.

${ }^{31}$ TITTE Arș. 39/ 14525.

${ }^{32}$ TİTE Arş. 39/14525, 14527, 14533. 
Çobanyan, Babacanyan, Safrastiyan, Aramozyan, Bogos Esmeryan, Abraham Kogasok getirildi ${ }^{33}$.

Mondros Mütarekesi'nin imzalanmasından sonra Ermenilerin bir kısmi Türklerin elinde bulunan bölgelerde yaşamayı sürdürürken, çoğunlukla, yıllardır Müslüman toplumla mücadelelere girmiş olanlar İstanbul ve İzmir'e göç etti. İstanbul'a gelenler içinde Anadolu'nun çeşitli yerlerinden (daha çok Adana, İzmit, Adapazarı, Düzce, Bahçecik hatta Erivan'dan gelenler vardı. Başlangıçta yer sorunları nedeniyle çadırlara yerleştirilen ${ }^{34}$ Göçmenler, işsizliğin de önemli boyutlara ulaşmasıyla büyük ölçüde komitelerin hizmetine girdi ${ }^{35}$.

Ermeni komitelerinin birleşmeleri sonrası, İşgalci İngiliz subaylarının aileleri Istanbul'u terk ederken, şehire gelen Ermeni komitecilerinin ve göçmenlerin sayısında artış görüldü ${ }^{36}$. Göçmenlerden Ermeniler Ortaköy, Beyoğlu, Üsküdar, Yenimahalle, Adalar; Rumlar Fener, Beyoğlu, Tatavla civarına yerleştirildiler ${ }^{37}$. İngiliz gizli servisinin direktifiyle oluşturulan bu yerleştirme politikasının ${ }^{38}$ bir boyutu ise Ermeni örgütlerinin karşı koymalarına rağmen göçmenlerin bir kısmının Gemlik ve Mudanya civarına yerleştirilmeleridir.Bu nedenle Gemlik, Mudanya bölgelerine adam gönderen komiteciler Ermeni ailelerin İstanbul'a dönmeleri yolunda propagandalar yaptılar. Bu bölgede Ermeni nüfus o denli artırıldı ki, İzmir'in Türk tarafına geçişinden sonra Gemlik-Mudanya bölgesindeki Ermeniler, İstanbul'da bulunan Mınak isimli bir Ermeniden, Kuva-yı Milliyecilerle savaşabilmek için silah ve mühimmat istediler. Gönderilen malzeme yolda yakalanınca Mınak tutuklandı ve İngilizlerin girişimiyle serbest bırakıldı ${ }^{39}$.

1922 Ocak ayında Ermeni Komiteciler, İstanbul'da gerçekleşecek olası ayaklanmayı organize etmek, Türk liderlere karşı suikastler düzenlemek amacıyla Tokatlıyan'da bir fedai derneği oluşturarak, gönüllü kayıtları yaptılar.Dernek Başkanlığına Tahtacıyan, yardımcılığına ise İblaganyan getirildi $^{40}$. Bu Derneğin Yönetim Kurulu üyelerinden, Paris'te bulunan General Antranik, aynı zamanda Ermeni Milli Müdafaa Heyeti Başkanı idi $^{41}$.

İzmir'in Türkler tarafından kurtarılması sonrası, İstanbul'daki Ermeni komiteleri arasında ayrılıklar baş gösterdi. Rum ve Ermeni komitelerinin İzmir'de olduğu gibi İstanbul'u yakmaları olasılığına karşı ${ }^{42}$ İngilizlerce

\footnotetext{
${ }^{33}$ TITE Arş. 39/14507, 14510. s.215.

${ }^{34}$ Ulubelen, Erol, İngiliz Gizli Belgelerinde Türkiye, Yaylacık Matb., İstanbul 1967.

${ }^{35}$ TITE Arş. 39/14599-3.

${ }^{36}$ TíTE Arș. 39/13275,14485, 14506

${ }^{37}$ TíTE Arş. 39/13258.

${ }^{38}$ TITE Ars. 39/14535.

${ }^{39}$ TITE Ars. 39/13245, 14401, 14535, 14588.

${ }^{40}$ Yönetim Kurulu, Jagadamard Gazetesi sahibi Vartanis Dikyan, General Antranik. Senmikyan, K. Tabalyan, Vahram Ekmekciyan ve Şevariş Misakyan idi.

${ }^{41}$ TITE Arş. 39/13262, 13243, 14556

${ }^{42}$ TiTE Arş. 39/14426, 14551.
} 
önlemler alındı ${ }^{43} .21$ Eylül'de yazılan bir haberalma belgesinde İstanbul'daki durum ve İngiltere'nin politikaları hakkında 'Anadolu'nun Yunan istilasindan tahlisi dolaytsiyla Istanbul'da tahaddïs eden vaziyet şehrimizdeki Ermeni ve Rum anasir arasinda fevkalade bir heyecan tevlid etmişdir. Bunlar arasında Türk ahali tarafindan Hiristiyanlara karşı bir katl yapılacağı şayia-i mütevattırdır. Anasır-ı merkumenin münevveranı arasında hüküm-ferma olan fikir ve kanaate nazaran İzmir'in istirdadını müteakib İstanbul'da yapılan nümayişler esnsında bazı çapulcu eşhas tarafindan mevzii bir mahiyetde kismen hıritiyanlara karşı icra edilen ve muayyen bir hedefi olmadığı Türk ve Türk düşmanı olan müessesata karşı da vuku bulan tecavïzatla sabit olan hasaratdan dolayl müteessir bulunan Türklerin katliam teşebbüsünde bulunmaları bade'l- ihtimal görülmekde ve hasaratı tazmin etmek suretiyle anasır-l hiristiyaniyeye karşı şayan-l takdir bir hamiyetkarlık göstermiş olan hükümetin böyle bir kitali katiyen tecviz ve müsamaha etmeyeceğine muhakkak nazarıyla bakılmakdadır. Ancak devletlerin Türk idaresi altında yaşayan ekalliyetler hakkında yeniden nazar-l dikkati celb etmek ve Türklerle yapllacak muahedede bunlara aid kuyud ve şurutu teşdid eylemek maksadiyla bazl vesileler ihdas etmek gayesini takib eden Ingiltere Hükümeti tarafindan bazı Türk esafilini ve taşradan gelen Ermeni ve Rum mültecileriyle çerkeslerden bir kısmını kaydetmek suretiyle bir teşkilat vücuda getirib bunları İstanbul'da küçük mikyasda bir kargaşalık ihdası ve katl icrasıyla tavzif etmekde oldukları istihbar kılınmışdır. Nitekim İstanbul'daki İngiliz ailelerinin bu günlerde İstanbul'u terk etmekde olmalarl da bu haberi teyid edecek bir buhran halidir. Ingilizlerin bu tertibatına muttali olan anasır-l merkume münevveran Ingiltere Hükümeti'nin ma_haza kendi amal-i mefsedetkaranelerinin husulünü teminen "ekalliyetler" perdesi altında şimdiye kadar icra etdikleri ve elyevm yine bu fikirle yapmakta olduklart tertibatın daima olduğu gibi Türk memleketlerinde yaşayan ve iktisaden hakim bir mevkii işgal eden Rum ve Ermeniler ve teveccüh etmiş olan iğbirar ve husumetin teşdidinden başka bir netice vermeyeceğine kanaat etmekde ve bu himaye teranesinden nefret ve adem-i memnuniyet beyan eylemekdedirler. Bu anasırın avamı arasında dahi duruma adem-i vukuf dolayısıla Türklerin bir katliamı musavveretinde şüyu bulan bu mesele havf ve heyecanın umumileşmesine badi olmakdadır. Anadolu'dan gelen Ermeni mültecilerinin Ortaköy cihetlerine ve Rum muhacirlerinin de Galata, Beyoğlu ve Fener menatıkına müctemian iskan edilmekde oldukları görülmüs ve bu mütemian iskan keyfiyetinin şehrin muhafaza-i sükunet ve asayişi nokta-i nazarından tehlikesi der-kar bulunmuşdur. Bu mültecilerin şehirde bir kargaşalık zuhurunda muntazam bir program tahtında iştiraklerini temin için küçük ve mahalli teşkilatlar vücuda getirilmekde olduğu da cümle-i müstehbaratdan bulunmuş olmăgla rapor takdim kllınır efendim. 21.9.338 Şevki" denmektedir ${ }^{44}$.

\footnotetext{
${ }^{43}$ TİTE Arş. 39/13258 (25.9.1922).

${ }^{44}$ TITTE Arș. 39/14536.
} 
Bu dönemde İstanbul'un Türklere geçme olasılığı artınca, Rum ve Ermeni derneklerinden kopmalar başladı. Bazı Taşnak partisi başkanları Yunanlıları, Ermenilerin yok edilişine neden olmakla suçladı ${ }^{45}$. Geçmişte Türkler aleyhine faaliyet gösteren komitecilerin çoğu Avrupa'ya kaçt, ${ }^{46}$. Bazı Taşnaksütyun başkanları dışında, fırkanın ileri gelenleri, Hınçak Partisi ve mutedil Hınçak Partisi üyeleri Türk yanlısı tavır aldılar ${ }^{47}$. Taşnaklar örgütten kopmaları önleyebilmek amacıyla toplantılar düzenledi ${ }^{48}$. Hatta Ekim 1922'de Ksantopoulos, Corciyadis, Epoyan ve Sağıryan'ın katıldığı bir toplantıda yeniden Ermeni-Rum komitelerinin işbirliği gündeme getirildiyse de girişim başarısızlıkla sonuçlandı ${ }^{49}$. 29 Ekim 1922'de Taşnak Fırkası Başkanı Amadoni, Fırka içinde Rumlarla işbirliği yapanları suçlayarak, bunun partinin siyasetiyle uyuşmadığını, İstanbul'da herhangi bir ayaklanma veya eylem hareketinin komiteleri için söz konusu olamayacağını açıkladı ${ }^{50}$. Buna karşın bu tarihten çok sonra İstanbul'a gelen bazı komitecilerin Rum kiliselerinde konuk edildiği Türk haberalma raporlarından anlaşılmaktadır ${ }^{51}$.

1922 Ekim sonunda, bazı Ermeni komitecilerin, Lozan da toplanması kararlaştırılan konferansa Ermeni Devleti kurulması istemiyle yazılı öneri verecekleri duyulunca Patrikhane kurulu topland, Arslanyan Patrikhane kaymakamlığına seçildi. Patrikhane, Ermeni davasından vazgeçtiklerini, Türklerle bir arada yaşamak istediklerini konferansa bildirmek üzere Lozan'a bir heyet göndermeyi kararlaştırdı ve bu heyetin yola çıkmadan önce komiteciler tarafından öldürülecekleri tehditleri ald $^{52}$. Lozan'da birleşik Ermeni heyeti, genel savaşta müttefiklerin yanında görevlerini yaparak çok kayıp verdiklerini, Ermeni sorununun bu konferansla çözümlenmesi gerektiğini belirtir bir muhtırayı konferansa sundu ${ }^{53}$. Patrikhanenin olumlu yaklaşımlarına karşın Zaven ile işbirliği yapan bir grup komiteci Arslanyan yerine kendi düşüncelerini destekleyen bir başkasının bu göreve getirilmesi yolunda girişimlerde bulunup, Kralgo-Armenien isimli bir dernek ile yakın ilişkiye girdilerse de, İstanbul'un Türklerin eline geçişi bu girişimleri sonuçsuz bıraktı.

\footnotetext{
${ }^{45}$ TİTE Arş. 39/14543.

${ }^{46}$ TITE Ars. 39/14560.

${ }^{47}$ TITE Arş. 39/14560; ATASE Arş. A.1/7895, K.1560, D.119, F.2/1.

${ }^{48}$ TITE Arş. 39/14539.

${ }^{49}$ TITE Ars. 39/14553.

${ }^{50}$ TiTE Arş. 39/13262.

${ }^{51}$ TITE Arş. 39/14569.

52 TiTE Ars. 39/14539.

${ }_{53}$ TITE Arş. 39/13246, 14539, 14576. Uras, Esat, Tarihte Ermeniler ve Ermeni Meselesi, Belge Yay., İstanbul 1987, s.710.
} 